\title{
Responses of life-history traits of brackish- and freshwater populations of the water strider to $\mathrm{NaCl}$ Aquarius paludum (Hemiptera: Gerridae)
}

\author{
MAnABu KISHI ${ }^{1}$, Tetsuo HARADA ${ }^{2}$ and KenJI FUJISAKI ${ }^{1}$ \\ ${ }^{1}$ Laboratory of Insect Ecology, Graduate School of Agriculture, Kyoto University, Kyoto 606-8502, Japan; \\ e-mail: kishi@hotmail.co.jp \\ ${ }^{2}$ Laboratory of Environmental Physiology, Graduate School of Integrated Sciences on Human and Nature, Kochi University, \\ Kochi, Japan; e-mail: haratets@kochi-u.ac.jp
}

Key words. Gerridae, water strider, brackish-water, life-history traits, population origin, rearing environment

\begin{abstract}
The water strider Aquarius paludum inhabits the surfaces of a wide variety of freshwater habitats both temporary and permanent. It can also live on the surface brackish-water around river mouths. Exposure to a brackish rather than freshwater environment may affect a range of adult and offspring life-history traits. In a two-stage experiment A. paludum offspring from fresh- (F) and brackish-water (B) populations were obtained and their offspring reared in either a fresh- or brackish-water $(0.45 \% \mathrm{NaCl})$ environments. The four offspring treatment groups (F-F, F-B, B-F, B-B) varied in terms of the parental and offspring rearing environments. The effect of parental and offspring rearing environment on longevity, fecundity and flight was assessed. Offspring reared in a brackish environment throughout their larval and adult stages had a reduced longevity and egg production. The flight activity of the offspring originated from the brackish-water population was maintained when they were reared in a brackish environment, but inhibited when they were exposed to freshwater. Our results suggest that the life-history strategies depend critically on the degree of salinity in both the current environment and that of their parents.
\end{abstract}

\section{INTRODUCTION}

Environmental change in a habitat is likely to affect the survival of the offspring of insects. Therefore, their ability to escape from unfavorable environments in space and time is particularly important. In insects this is achieved by changes in traits such as reproduction, migration and diapause. The "habitat template" theory of the evolution of life-history strategies in insects suggests that the temporal and spatial characteristics of the habitat mould and select for specific life history traits (Southwood, 1977). However, resources such as food and time are limited. Thus, insects need to allocate resources appropriately in order to prepare for an unpredictable situation in the future. The "trade-off" in the allocation of the resource is well illustrated by the relationship between migratory and reproductive traits, i.e., oogenesis-flight syndrome (Johnson, 1969), in insects such as aphids (Dixon et al., 1993), crickets (Tanaka \& Suzuki, 1998), chinch bugs (Fujisaki, 1986), water striders (Harada \& Nishimoto, 2007) etc. On the other hand, in many insects, life-history traits are influenced by population variation and parental effects. For example, in the locust Schistocerca gregaria, the density of adults affects phase change and several traits in offspring (Bouaichi \& Simpson, 2003).

Water striders (Gerridae) occur in various aquatic habitats. Their widespread worldwide distribution, even occupation of oceanic areas (excluding the North and South poles) is associated with this physiological plasticity (Spence \& Andersen, 1994; Andersen, 2000). They are able to colonise and adapt to severe environmental condi- tions by means of reproductive and migratory trade-offs or bet-hedging (Vepsäläinen, 1978; Spence \& Andersen, 1994; Harada et al., 2000; Kishi et al., 2002; Harada, $2003 \mathrm{a}, \mathrm{b})$. Thus, the evolution of life-history strategies in water striders has provoked a great deal of discussion (Spence, 1989; Fairbairn \& Butler, 1990; Murray \& Giller, 1990; Kaitala, 1991; Klingenberg \& Spence, 1997).

Water striders can use brackish-water habitats inhabited by few aquatic insects, as refuges or temporary reproductive areas (Vepsäläinen, 1978; Kishi et al., 2007). However, occupying a brackish habitat during the larval or adult stage inhibits the reproduction and/or flight activity and shortens the life span of the water strider Aquarius paludum (Fabricius) (Kishi et al., 2006, 2007). These studies indicate that the water strider's plasticity is based on its physiological response to $\mathrm{NaCl}$ in the habitat. For larvae of Gerris thoracicus (Vepsäläinen, 1978) and $A$. paludum (Kishi et al., 2006) have a large developmental period in brackish-water habitats. If water striders inhabit brackish-water habitats for several generations, natural selection favours those better adapted to brackish-waters conditions. However, although there are many studies on the salinity tolerance of freshwater invertebrates other than insects (Berezina, 2003; Kefford et al., 2004, 2005), there are none on freshwater insects. There are no ecophysiological studies on the adaptation of originally fresh water invertebrates to brackish-water habitats. In this study, the responses to exposure to saline conditions of the life-history traits of $A$. paludum populations colonizing freshwater and brackish-water habitats are compared. 
TABLE 1. Effects of four treatments on larval development, survival to adult emergence, adult longevity and reproductive traits of A. paludum. F-F, F-B, B-F and B-B denote first the population of origin and the second the laboratory rearing environment. Different letters denote statistically significant differences $(P<0.05)$ (applied Bonfferoni correction) between treatment groups.

\begin{tabular}{|c|c|c|c|c|c|c|c|c|}
\hline & \multicolumn{4}{|c|}{ Freshwater population } & \multicolumn{4}{|c|}{ Brackish-water population } \\
\hline & & F-F & & F-B & & B-F & & B-B \\
\hline $\begin{array}{l}\text { Developmental time (days) } \\
(\mathrm{n}, \mathrm{ME} \pm \mathrm{SE})\end{array}$ & 278 & $30.1^{\mathrm{a}} \pm 0.07$ & 218 & $30.3^{\mathrm{ab}} \pm 0.07$ & 258 & $29.8^{c} \pm 0.06$ & 227 & $30.4^{\mathrm{b}} \pm 0.08$ \\
\hline $\begin{array}{l}\text { Survival to adult emergence } \\
(\mathrm{n}, \%)\end{array}$ & 320 & $86.9^{\mathrm{a}}$ & 320 & $68.1^{\mathrm{b}}$ & 320 & $80.9^{\mathrm{ac}}$ & 320 & $70.9^{\mathrm{bc}}$ \\
\hline $\begin{array}{l}\text { Percentage of long winged } \\
\text { individuals }(\mathrm{n}, \%)\end{array}$ & 275 & 96.4 & 216 & 99.1 & 252 & 96.0 & 227 & 97.8 \\
\hline $\begin{array}{l}\text { Longevity (days) } \\
(\mathrm{n}, \mathrm{ME} \pm \mathrm{SE})\end{array}$ & 158 & $61.9^{\mathrm{a}} \pm 2.12$ & 161 & $49.9^{\mathrm{b}} \pm 1.87$ & 160 & $57.3^{\mathrm{ab}} \pm 2.02$ & 154 & $48.1^{\mathrm{bc}} \pm 2.32$ \\
\hline $\begin{array}{l}\text { Preoviposition period (days) } \\
(\mathrm{n}, \mathrm{ME} \pm \mathrm{SE})\end{array}$ & 70 & $23.5^{\mathrm{a}} \pm 0.78$ & 67 & $21.7^{\mathrm{ab}} \pm 0.55$ & 70 & $21.8^{\mathrm{ab}} \pm 0.59$ & 62 & $20.7^{\mathrm{b}} \pm 0.58$ \\
\hline $\begin{array}{l}\text { Total number of eggs laid } \\
(\mathrm{n}, \mathrm{ME} \pm \mathrm{SE})\end{array}$ & 70 & $344.9^{\mathrm{a}} \pm 28.6$ & 67 & $216.1^{b} \pm 24.6$ & 70 & $325.8^{\mathrm{ab}} \pm 33.7$ & 62 & $287.5^{\mathrm{ab}} \pm 39.8$ \\
\hline $\begin{array}{l}\text { Oviposition rate } \\
(\mathrm{n}, \mathrm{ME} \pm \mathrm{SE})\end{array}$ & 69 & $4.99^{\mathrm{a}} \pm 0.35$ & 67 & $3.64^{\mathrm{ab}} \pm 0.32$ & 70 & $6.23^{\mathrm{ac}} \pm 0.82$ & 62 & $4.28^{\mathrm{a}} \pm 0.42$ \\
\hline
\end{tabular}

\section{MATERIAL AND METHODS}

Thirty pairs of adults of $A$. paludum were collected in late July 2003 from a freshwater habitat on the upper Kagami River $(0 \% \mathrm{NaCl}$ concentration at the collection site), and brackishwater habitat, Daizen pond at the mouth of Shimoda river $(0.45 \%)$, Kochi City $\left(33^{\circ} \mathrm{N}\right)$, Kochi Prefecture, Japan. Similarly, thirty pairs were collected in 2004 from a paddy field (0\%) and a brackish-water habitat at the mouth of the Niyodo river $(0.3 \%)$, Kochi City and Ino City $\left(33^{\circ} \mathrm{N}\right)$, respectively. Adults from the fresh- and brackish-water populations and the eggs they laid, were maintained on $0 \%$ and $0.45 \% \mathrm{NaCl}$ solutions, respectively, at a $15.5 \mathrm{~L}: 8.5 \mathrm{D}$ photoperiod and $20 \pm 2{ }^{\circ} \mathrm{C}$. The populations were defined as freshwater or brackish-water populations by their "population origin".

Newly hatched first instar larvae derived from the eggs that were laid and developed in fresh or brackish-water environments were used in the experiment. Larvae were selected at random. These environments were defined as freshwater and brackish-water environments, respectively. The first instar larvae of each strain were reared to the adult stage on a $0 \%$ or $0.45 \% \mathrm{NaCl}$ solution in the laboratory. Thus, there were four experimental groups: F-F; F-B; B-F; B-B. (F - freshwater; B brackish-waters; the first letter refers to the habitat from which the original population was collected and the latter to the laboratory rearing environment)

There were eight trials per experimental group. Each trial consisted of 20 larvae selected at random, which were reared in plastic containers $(34 \mathrm{~cm} \times 23.5 \mathrm{~cm} \times 4.5 \mathrm{~cm})$, from hatching to adult emergence, at a $15.5 \mathrm{~L}: 8.5 \mathrm{D}$ photoperiod and $20 \pm 2{ }^{\circ} \mathrm{C}$. Adult blowflies, Lucilia illustris, were provided as food every day, at a rate of one fly per five first or second instar individuals, one fly per three third or fourth instar individuals, and one fly per two fifth instars. At adult emergence, whether the wings were long or short was recorded. Pairs of long winged individuals each placed in round plastic containers $(14 \mathrm{~cm}$ in diameter $\times 5 \mathrm{~cm}$ in height) just after adult emergence and provided with one adult L. illustris each day. Wooden sticks floating on the water provided the striders with sites for egg laying and resting. The rearing conditions, a $15.5 \mathrm{~L}: 8.5 \mathrm{D}$ photoperiod and $20 \pm 2{ }^{\circ} \mathrm{C}$, promote reproduction (Harada, 1992, 1993). Life-history traits such as reproduction, migration and longevity were assessed. The number of eggs laid by each female was counted every two days until death. The number of eggs laid per female per day was the "oviposition rate". The flight propensity of all adults was evaluated on the 30th day after emergence. Following the method of Harada et al. (1997), we recorded whether the flight behaviour of each individual was modified by blue light (about $3400 \mathrm{Lx}$ ) at a high temperature $\left(32 \pm 2^{\circ} \mathrm{C}\right)$.

\section{RESULTS}

\section{Developmental time, survival rate}

Development was prolonged when the offspring developed in a brackish environment (Tables 1, 2a). In contrast, development was shortened when offspring of the brackish-water population were reared in a freshwater environment (Table 1). The survival of the offspring reared in a brackish environment was lower than that of those reared in a freshwater environment. The percentage survival of offspring originating from the fresh water population and reared in a brackish environment was much lower than that of those originating from a brackish population and reared in a brackish environment (Tables $1,3 a)$.

\section{Longevity and reproductive traits}

Adult longevity was affected not by sex, but by the salinity of the water of the environment in which they developed (Tables 1, 2b). Adult longevity of offspring reared in a brackish environment was significantly shorter than that of offspring reared in a freshwater environment (Table 1). When offspring were exposed to a brackish environment, the length of the pre-oviposition period was shortened. The preoviposition period of the brackish population was also significantly shorter than that of the fresh water population (Tables 1, 2c). Adults that developed in a brackish environment laid few eggs (Tables 1, $2 d)$. The oviposition rate of offspring reared in a freshwater environment was significantly higher than that of those reared in a brackish-water environment (Tables 1, 2e). The brackish-water population tended to have a 
TABle 2. ANOVA of the effect of four treatments on longevity and reproductive traits of $A$. paludum $(* P<0.05 ; * * P<0.01 ; * * * P<0.001)$.

\begin{tabular}{lcccc}
\hline & df & SS & $F$ & $P$ \\
\hline $\begin{array}{l}\text { (a) Developmental time } \\
\quad\end{array}$ & 1 & 1.096 & 0.920 & 0.338 \\
$\quad \begin{array}{l}\text { Population origin } \\
\text { Rearing environment }\end{array}$ & 1 & 41.675 & 34.951 & $<0.001^{* * *}$ \\
$\quad \begin{array}{l}\text { Population origin } \times \text { rearing environment } \\
\text { (b) Longevity }\end{array}$ & 1 & 12.617 & 10.581 & $0.001^{* *}$ \\
$\quad$ Sex & 1 & 541.262 & 0.783 & 0.377 \\
$\quad$ Population origin & 1 & 1618.689 & 2.340 & 0.127 \\
$\quad$ Rearing environment & 1 & 17734.478 & 25.641 & $<0.001^{* * *}$ \\
$\quad$ Population origin $\times$ rearing environment & 1 & 312.943 & 0.452 & 0.501 \\
(c) Preoviposition period & & & & \\
$\quad$ Population origin & 1 & 124.452 & 4.528 & $0.034^{*}$ \\
$\quad$ Rearing environment & 1 & 140.319 & 5.106 & $0.025^{*}$ \\
$\quad$ Population origin $\times$ rearing environment & 1 & 7.662 & 0.279 & 0.598 \\
(d) Number of eggs laid & & & & \\
$\quad$ Population origin & 1 & 45995.006 & 0.673 & 0.413 \\
$\quad$ Rearing environment & 1 & 468018.227 & 6.848 & $0.009^{* *}$ \\
$\quad$ Population origin $\times$ rearing environment & 1 & 137222.703 & 2.008 & 0.158 \\
(e) Oviposition rate & & & & \\
$\quad$ Population origin & 1 & 59.585 & 3.161 & 0.077 \\
$\quad \begin{array}{l}\text { Rearing environment } \\
\text { Population origin } \times \text { rearing environment }\end{array}$ & 1 & 182.183 & 9.665 & $0.002^{* *}$ \\
\hline
\end{tabular}

higher ovipositon rate than the freshwater population (Tables 1, 2e). There were significant positive correlations between longevity and the number of eggs laid in the three experimental groups of F-F, F-B and B-B, but not in group B-F (Fig. 1).

\section{Migratory traits}

The percentage of long winged individuals increased when offspring were reared in a brackish compared to a freshwater environment (Tables 1, 3b). However, the percentage of the long winged individuals was unrelated to the origin of the population (Table $3 \mathrm{~b}$ ). Flight propensity was related to sex and to interaction between population origin and rearing environment (Tables 1, 3). The flight propensity of group B-F was significantly lower than that of the other experimental groups F-F, F-B and B-B $\left(\chi^{2}\right.$ test: $\chi_{\text {cal }}^{2}=38.00, d f=3, P<0.001$; Fig. 2$)$. The peak in their flight response was also delayed by exposure to a brackish environment (Kolmogorov-Smirnov's test: $\mathrm{z}=$ 1.789, $P=0.003$ for rearing environment; $\mathrm{z}=0.553, P=$ 0.920 for population origin; Fig. 2).

\section{DISCUSSION}

\section{Effect of population origin and rearing environment on larval fitness}

The brackish environment had a detrimental effect on the larval development and survival of the freshwater population (Table 1), probably due to physiological stress. This finding accords with that of previous studies (Vepsäläinen, 1978; Kishi et al., 2006). Exposure to brackish-water may result in an increase in the osmotic pressure of the haemolymph of larvae.

\section{Effects of population origin and rearing environment} on longevity, reproduction and migratory status

The longevity of freshwater adults decreased in the brackish-water environment. The longer lifespan of females reared in a freshwater environment resulted in a higher fecundity than in the brackish-water environment (Fig. 1), although few reports have correlated fecundity

TABLE 3. Wald $\chi^{2}$-test following logistic regression analysis of the effect of four treatments on the survival to adult and the flight propensity of $A$. paludum $\left({ }^{*} P<0.05\right.$; ${ }^{* *} P<0.01$; ${ }^{* *} P<$ 0.001).

\begin{tabular}{|c|c|c|c|}
\hline Factors & & Wald $\chi^{2}$ & $P$ \\
\hline \multicolumn{4}{|l|}{ (a) Survival to adult emergence } \\
\hline Population origin & 1 & 1.461 & 0.227 \\
\hline Rearing environment & 1 & 31.283 & $<0.001 * * *$ \\
\hline Population origin $\times$ rearing environment & 1 & 5.714 & $0.017^{*}$ \\
\hline \multicolumn{4}{|l|}{ (b) Percentage of long winged individuals } \\
\hline Population origin & 1 & 0.522 & 0.470 \\
\hline Rearing environment & 1 & 4.478 & $0.035^{*}$ \\
\hline Population origin $\times$ rearing environment & 1 & 0.199 & 0.656 \\
\hline \multicolumn{4}{|l|}{ (c) Flight } \\
\hline Sex & 1 & 16.568 & $<0.001 * * *$ \\
\hline Population origin & 1 & 28.944 & $<0.001 * * *$ \\
\hline Rearing environment & 1 & 12.096 & $0.001^{* * *}$ \\
\hline Population origin $\times$ rearing environment & 1 & 19.646 & $<0.001 * * *$ \\
\hline
\end{tabular}



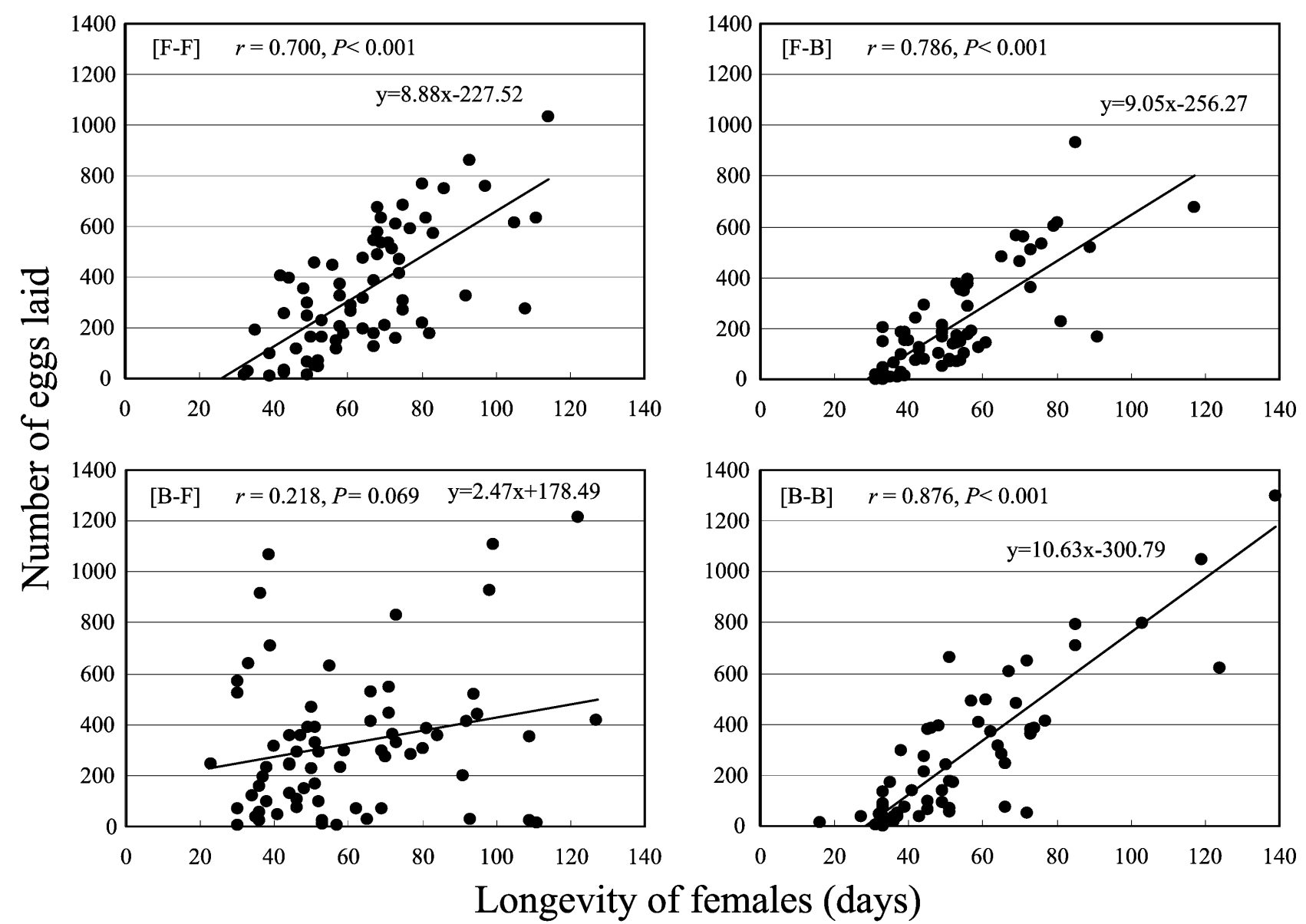

Fig. 1. Effect of four treatments on the relationships between longevity and number of eggs laid by A. paludum. The four graphs show the results for (F-F), the offspring of a freshwater population reared in a freshwater environment; (F-B) those of a freshwater population reared in a brackish-water environment; (B-F) those of a brackish-water population reared in a freshwater environment; and (B-B) those of a brackish-water population reared in a brackish-water environment, respectively.

with longevity in other water striders (Spence \& Andersen, 1994). On the other hand, the offspring of the brackish-water population compensated somewhat for the shorter longevity by a higher oviposition rate, which may have implications if mortality is higher in the field than in the laboratory. The brackish-water population exposed to freshwater did not allocate resources to dispersal but to increased reproductive activity (short preoviposition period and high fecundity), which may be an example of the "oogenesis-flight syndrome" (Johnson, 1969). This response may serve as another compensation for the lower fitness in the previous generation in the brackishwater environment.

Thus, the parameters of reproductive performance (earlier onset of reproduction and higher fecundity) in the brackish environment were enhanced by the brackish population as compensation for the previous lower fitness in a brackish-water environment. Other studies record that the lower fitness of aquatic organisms living in brackish habitats is due to physiological stress associated with salinity adversely affecting larval development, body size, survival, reproduction, etc. (caddis fly: Haage, 1968; mayfly: Chadwick \& Feminella, 2001; toad: Robert et al., 1998; Gomez-Mestre \& Tejedo, 2003). Thus, the adapta- tion to salinity may occur in the parents and during embryonic development. The brackish-water population may develop a flexible system that controls the osmotic pressure of haemolymph. The fecundity of brackish-water populations of the anuran, Bufo calamita, does not increase when reared in freshwater, as its tolerance of high salinity is genetically determined (Gomez-Mestre \& Tejedo, 2003). On the other hand, the peak in flight activity of brackish population offspring was delayed when they were reared in a brackish-water environment, most likely because flight muscle development was inhibited by the salinity induced physiological stress.

\section{Ecological significance of population origin and rearing environment}

Rearing in a brackish-water environment decreased longevity and fecundity in A. paludum, irrespective of the population origin. The brackish habitat appears to be unsuitable for freshwater animals (Kelts, 1979; Venkatesan, 1981; Chadwick \& Feminella, 2001; Silverbush et al., 2005). However, A. paludum populations occur in brackish habitats where the $\mathrm{NaCl}$ concentration is relatively low, such as the mouths of rivers and wilderness lakes (Kishi et al., 2007, unpubl. data). Although exposure to an abrupt increase in $\mathrm{NaCl}$ concentration at adult 

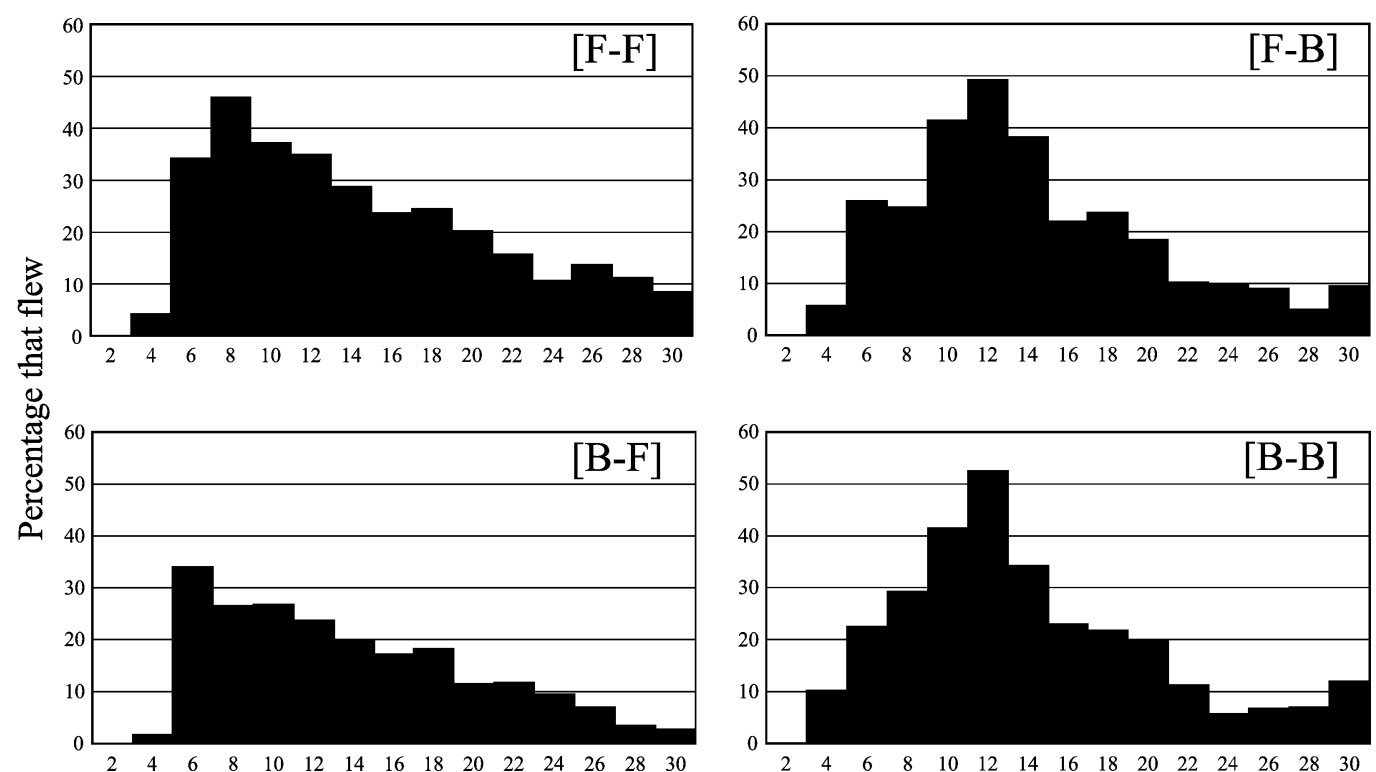

Days after adult emergence

Fig. 2. Effects of four treatments on the incidence of flight in A. paludum. The four graphs show the results for the F-F, F-B, B-F and B-B respectively. The first capital letters denote population of origin and the second the laboratory rearing environment.

emergence promotes flight in A. paludum (Kishi et al., 2006, 2007), long term exposure to a constant $\mathrm{NaCl}$ concentration did not. Instead, the strategy in brackish environments seems to be to "breed here and now" (Southwood, 1977). In this study, the flight propensity of group B-F was significantly lower than that of experimental groups F-F, F-B and B-B. The brackish population also adopted the "breed-here-and-now" strategy in freshwater to compensate for the lower fitness of the previous generation in the brackish-water environment.

By living in low $\mathrm{NaCl}$ brackish-water habitats the water striders may avoid the negative effects of salinity, such as shorter longevity and lower larval survival. Moreover, in brackish-water habitats with a relatively low $\mathrm{NaCl}$ concentration of less than $0.9 \%$, water striders might find rich insect food resource of mayflies, caddis flies, stoneflies, etc. (Williams \& Williams, 1998; Chadwick \& Feminella, 2001; Kefford et al., 2004, 2005). In addition, the number of predators may be relatively low in brackish-water habitats. For example, with the exception of a few species, such as B. calamita (Beebee, 1985; Gomez-Mestre \& Tejedo, 2003), most amphibians avoid inhabiting and breeding in saline and brackish environments, because of their poor osmo-regulatory ability (Balinsky, 1981; Boutilier et al., 1992). Thus, A. paludum may benefit from the security of brackish-water environments, despite costs associated with the physiological stress of salinity.

ACKNOWLEDGEMENT. This work was supported in part by the 21st Century COE program for Innovative Food and Environmental Studies Pioneered by Entomomimetic Sciences, from the Ministry of Education, Culture, Sports, Science, and Technology of Japan.

\section{REFERENCES}

ANDERSEN N.M. 2000: The evolution of dispersal dimorphism and other life history traits in water striders (Hemiptera: Gerridae). Entomol. Sci. 3: 187-199.

BALINSKY J.B. 1981: Adaptation of nitrogen metabolism to hypertonic environment in Amphibia. J. Exp. Zool. 215: 335-350.

BeEbee T.J.C. 1985: Salt tolerances of natterjack toad (Bufo calamita) eggs and larvae from coastal and inland populations in Britain. Herpetol. J. 1: 14-16.

BEREZINA N.A. 2003: Tolerance of freshwater invertebrates to changes in water salinity. Russ. J. Ecol. 34: 261-266 [in Russian with English abstr.].

Bouaich A. \& Simpson S.J. 2003: Density-dependent accumulation of phase characteristics in a natural population of the desert locust Schistocerca gregaria. Physiol. Entomol. 28: 25-31.

Boutilier R.G., Stiffler D.F. \& Toews D.P. 1992: Exchange of respiratory gases, ions, and water in amphibious and aquatic amphibians. In Feder M.E. \& Burggren W.W. (eds): Environmental Physiology of the Amphibians. Univ. of Chicago Press, Chicago, IL, pp. 81-124.

Chadwick M.A. \& Feminella J.W. 2001: Influence of salinity and temperature on the growth and production of a freshwater mayfly in the Lower Mobile River, Alabama. Limnol. Oceanogr. 46: 532-542.

Dixon A.F.G., North S. \& Kindlmann P. 1993: Migration in insect: Cost and Strategies. J. Anim. Ecol. 62: 182-190.

FAIRBAIRN D.J. \& BUTLER T.C. 1990: Correlated traits for migration in the Gerridae (Hemiptera, Heteroptera): a field test. Ecol. Entomol. 15: 131-142.

FUISAKI K. 1986: Reproductive properties of the oriental chinch bug, Cavelerius saccharivorus Okajima (Heteroptera: Lygaeidae) in relation to its wing polymorphism. Res. Popul. Ecol. 28: $43-52$.

Gomez-Mestre I. \& Tejedo M. 2003: Local adaptation of an anuran amphibian to osmotically stressful environments. Evolution 57: 1889-1899. 
HaAge P. 1968: On the salinity tolerance of eggs and young larvae of Phryganea grandis Linne (Trichoptera). Hydrobiologia 32: 257-270.

HARADA T. 1992: The oviposition process in two direct breeding generations in a water strider, Aquarius paludum (Fabricius). J. Insect Physiol. 38: 231-244.

HARADA T. 1993: Reproduction by overwintering adults of water strider, Aquarius paludum (Fabricius). Zool. Sci. 10: 313-319.

HARADA T. 2003a: Hardiness to low temperature and drought in a water strider, Aquarius paludum, in comparison with other insect groups. Trends Entomol. 3: 29-41.

HARADA T. 2003b: Comparative study of diapause regulation and life history traits among the four species of the water striders, Aquarius paludum, Gerris latiabdominis, G. nepalensis, and G. gracilicornis. In Recent Research Developments in Entomology, 2003. Research Signpost. Vol. 4. Kerala, India, pp. 77-98.

HaRAdA T. \& Nishimoto T. 2007: Feeding conditions modify the photoperiodically induced dispersal of the water strider, Aquarius paludum (Heteroptera: Gerridae). Eur. J. Entomol. 104: 33-37.

HaRAdA T., TABUChI R. \& KouRA J. 1997: Migratory syndrome in the water strider, Aquarius paludum (Heteroptera: Gerridae) reared in high versus low nymphal densities. Eur. $J$ Entomol. 94: 445-452.

Harada T., Inoue T., Ono I., Kawamura N., Kishi M., Doi K., InOUE S. \& Hodková M. 2000: Endocrine, ecophysiological and ecological aspects of seasonal adaptations in a water strider, Aquarius paludum (a mini review). Entomol. Sci. 3: $157-165$

Johnson C.G. 1969: Migration and Dispersal of Insects by Flights. Methuen, London, 763 pp.

KaItala A. 1991: Phenotypic plasticity in reproductive behaviour of water striders: tradeoffs between reproduction and longevity during food stress. Func. Ecol. 5: 12-18.

Kefford B.J., Dalton A., Palmer C.G. \& Nugegoda D. 2004: The salinity tolerance of eggs and hatchlings of selected aquatic macroinvertebrates in south-east Australia and South Africa. Hydrobiologia 517: 179-192.

Kefford B.J., Palmer C.G. \& Nugegoda D. 2005: Relative salinity tolerance of freshwater macroinvertebrates from the south-east Eastern Cape, South Africa compared with the Barwon Catchment, Victoria, Australia. Mar. Freshwater Res. 56: $163-171$.

KeLts L.J. 1979: Ecology of a tidal marsh corixid, Trichocorixa verticalis (Insecta, Hemiptera). Hydrobiologia 64: 37-57.
Kishi M., Harada T. \& Spence J.R. 2002: Adult flight in a water strider exposed to habitat dry-down in the larval stages. Naturwissenschaften 89: 552-554.

Kishi M., FuJisaki K. \& Harada T. 2006: How do water striders, Aquarius paludum, react to brackish-water simulated by $\mathrm{NaCl}$ solutions? Naturwissenschaften 93: 33-37.

Kishi M., Harada T. \& FujISAKI K. 2007: Dispersal and reproductive responses of the water strider, Aquarius paludum (Hemiptera: Gerridae), to changing $\mathrm{NaCl}$ concentrations. Eur. J. Entomol. 104: 377-383.

Klingenberg C.P. \& Spence J.R. 1997: On the role of body size for life-history evolution. Ecol. Entomol. 22: 55-68.

Murray A.M. \& GiLler P.S. 1990: The life-history of Aquarius najas De Geer (Hemiptera: Gerridae) in southern Ireland. Entomologist 109: 53-64.

Robert J.D., Nooshan M. \& Marnie P. 1998: Adaptive plasticity in amphibian metamorphosis: response of Scaphiopus hammondii tadpoles to habitat desiccation. Ecology 79: $1859-1872$.

Silberbush A., Blaustein L. \& Margalith Y. 2005: Influence of salinity concentration on aquatic insect community structure: a mesocosm experiment in the Dead Sea Basin Region. Hydrobiologia 548: 1-10.

Southwood T.R.E. 1977: Habitat, the templet for ecological strategies? J. Anim. Ecol. 46: 335-365.

SPENCE J.R. 1989: The habitat templet and life history strategies of pondskaters (Heteroptera: Gerridae): reproductive potential, phenology and wing dimorphism. Can. J. Zool. 67: $2728-2738$.

Spence J.R. \& ANDERSEN N.M. 1994: Biology of water striders: interactions between systematics and ecology. Annu. Rev. Entomol. 39: 101-128.

TANAKA S. \& SuZUKi Y. 1998: Physiological trade-offs between reproduction, flight capability and longevity in a wingdimorphic cricket, Modicogryllus confirmatus. J. Insect Physiol. 44: 121-129.

VEPSÄLÄINEN K. 1978: Wing dimorphism and diapause in Gerris: determination and adaptive significance. In Evolution of Insect Migration and Diapause. Springer, New York, NY, pp. 218-253.

VenKATESAN P. 1981: Influence of temperature and salinity variations on an aquatic bug population in a tropical pond. Hydrobiologia 79: 33-50.

Williams D.D. \& Williams N.E. 1998: Aquatic insects in an estuarine environment: densities, distribution and salinity tolerance. Freshwater Biol. 39: 411-421.

Received December 17, 2007; revised and accepted November 13, 2008 